\title{
Flávia Ribeiro
}

A noite me compõe 


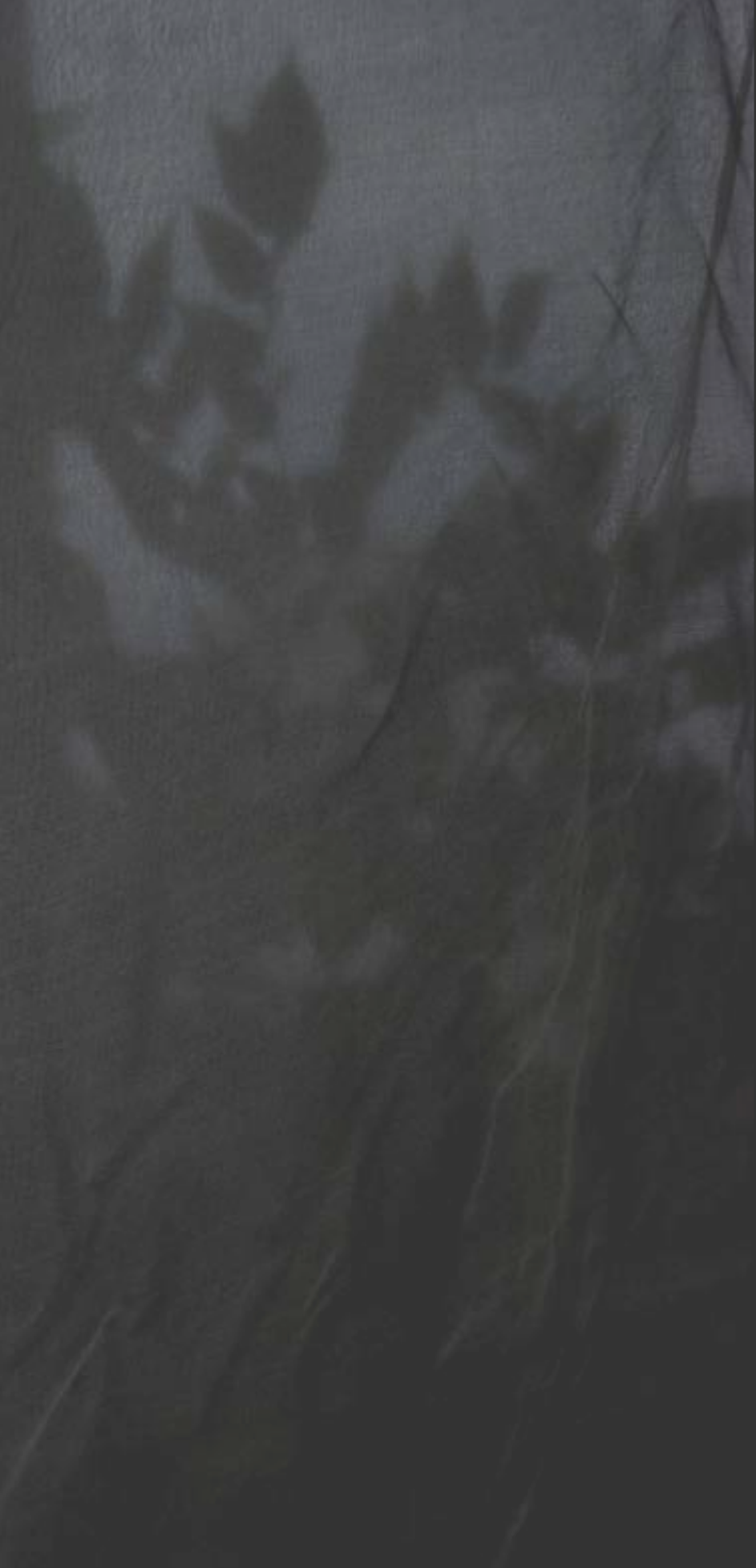




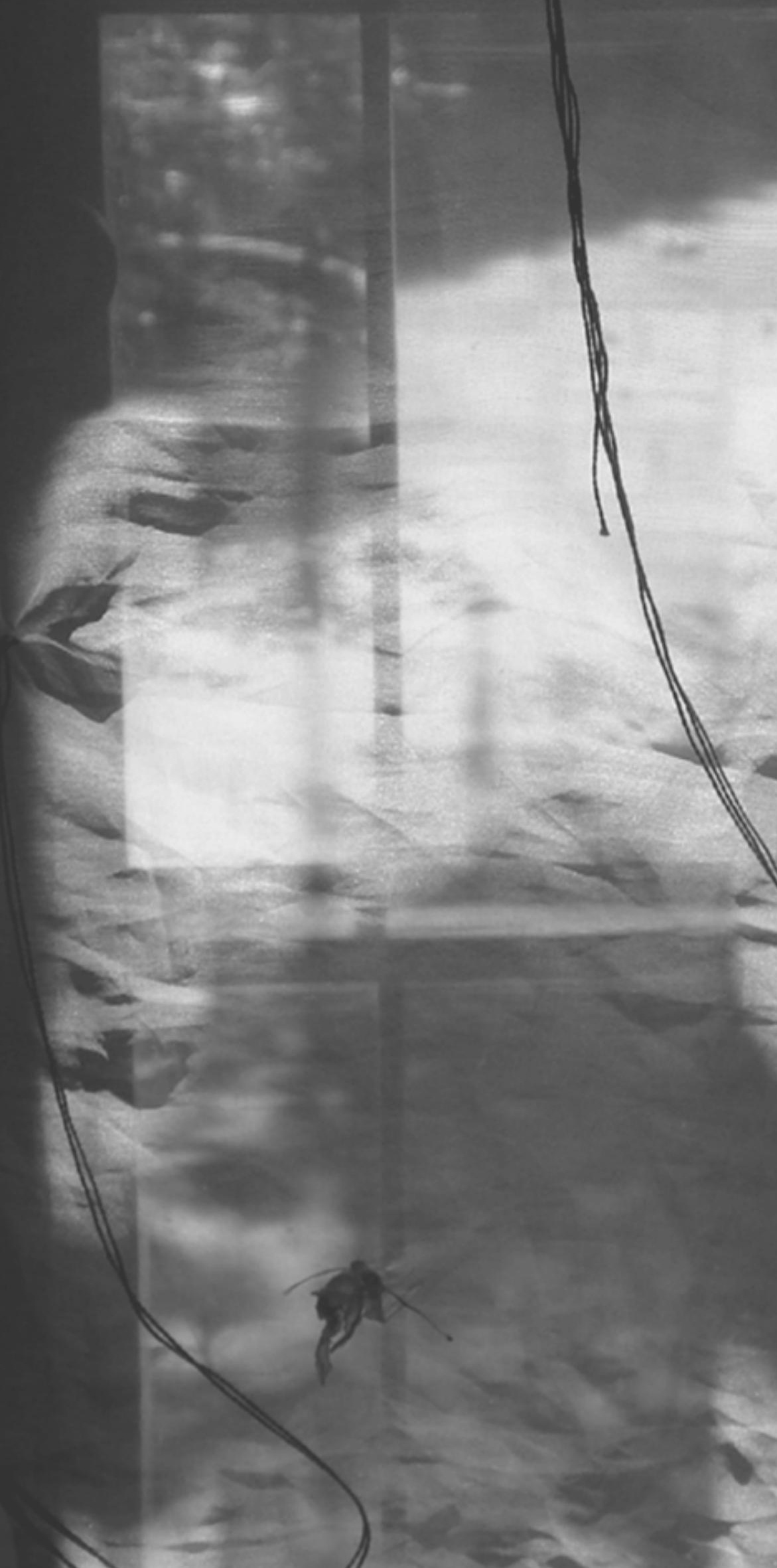




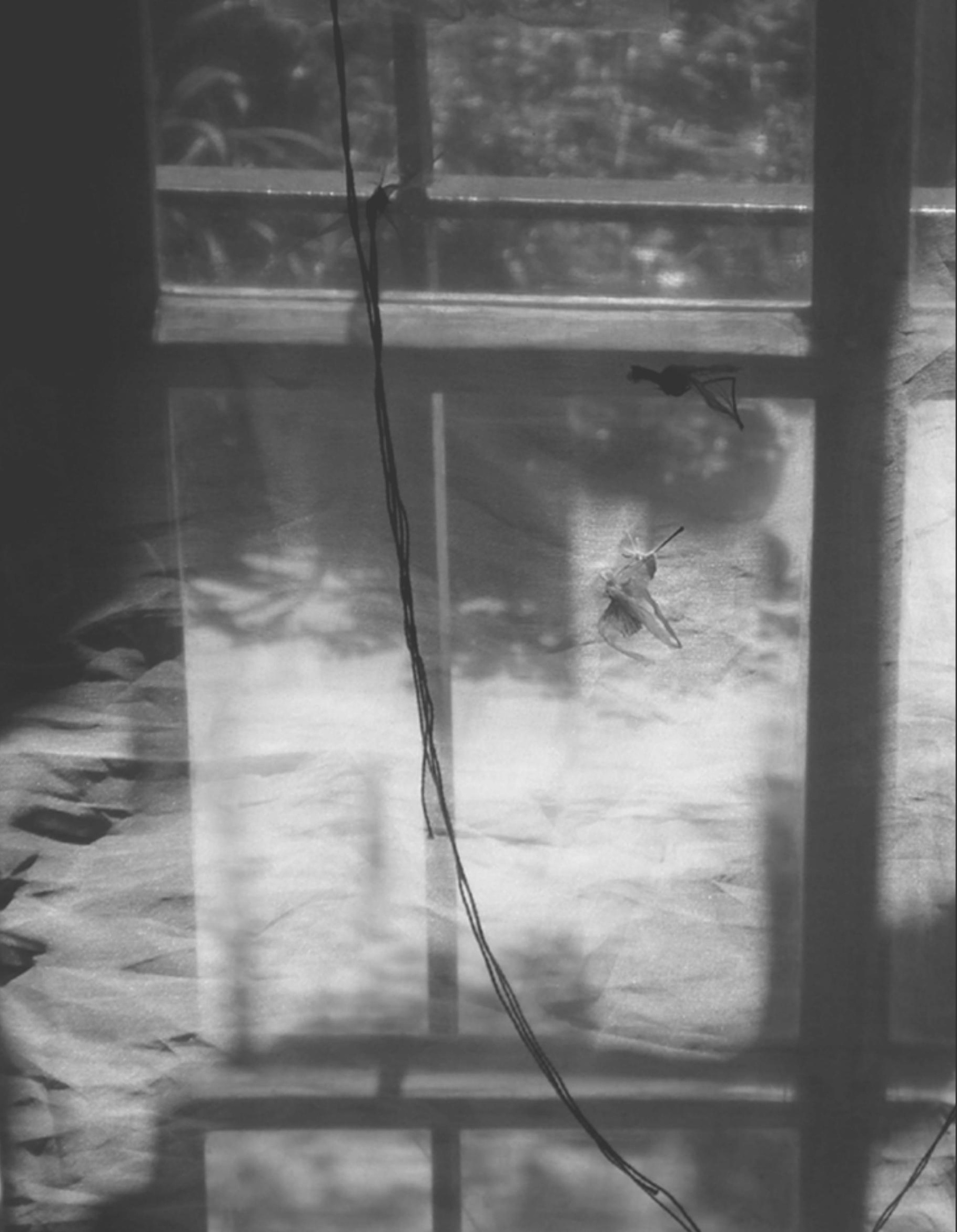





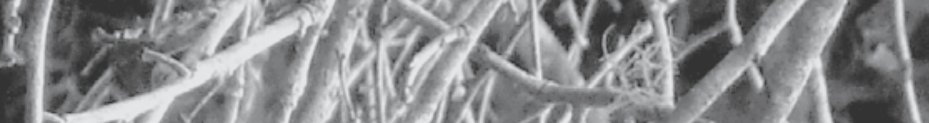

S.

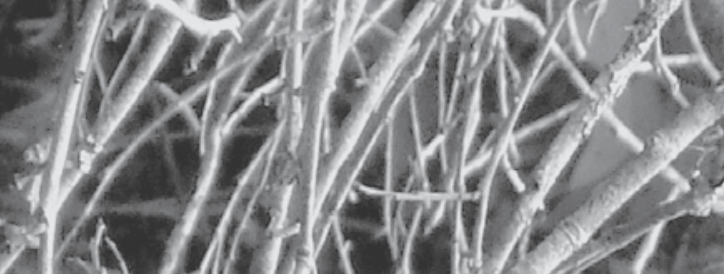

\section{is 40,0

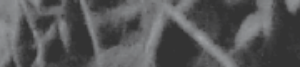

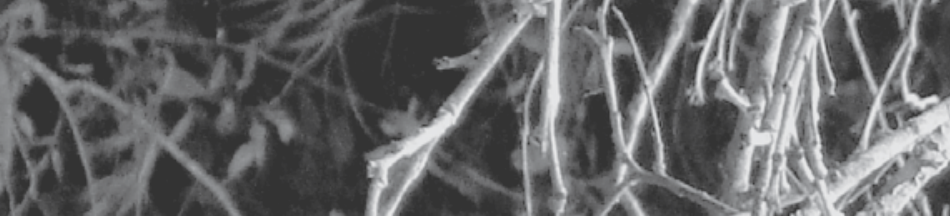

8.

(1)

(1)

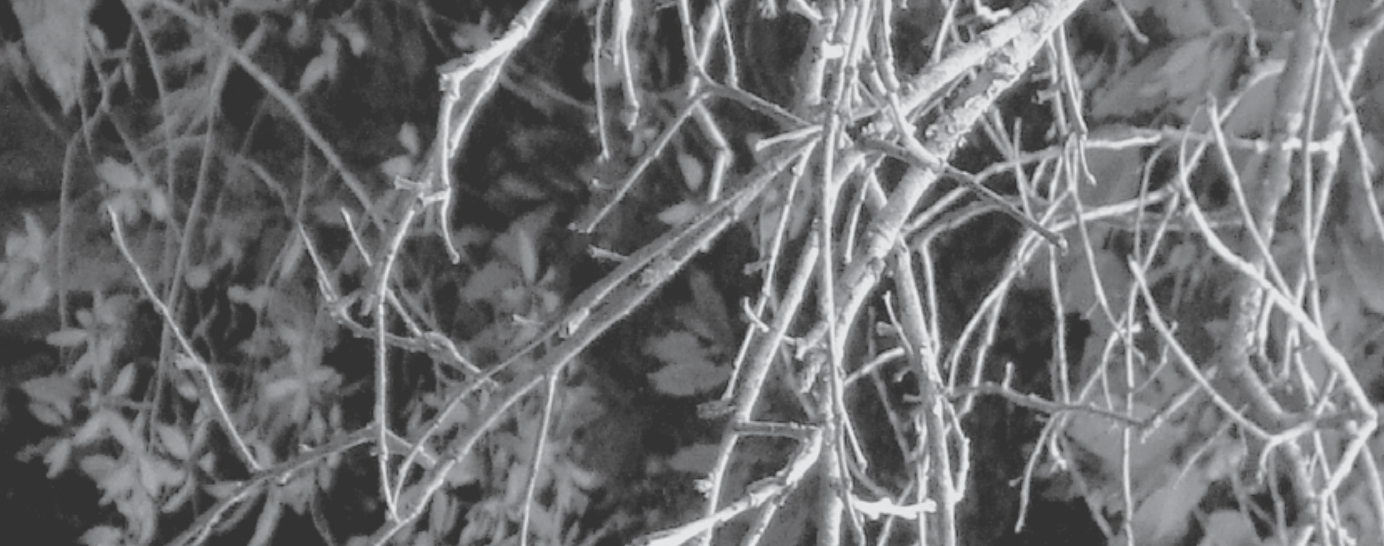

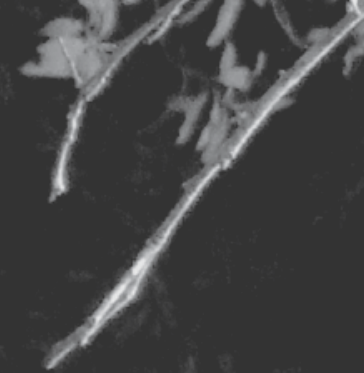

(1)

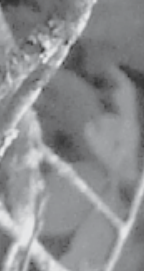





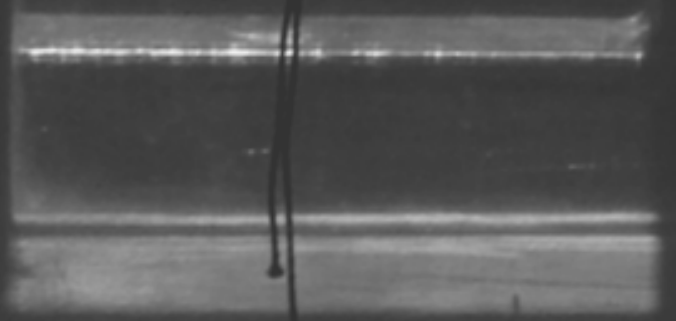

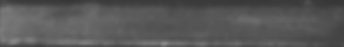
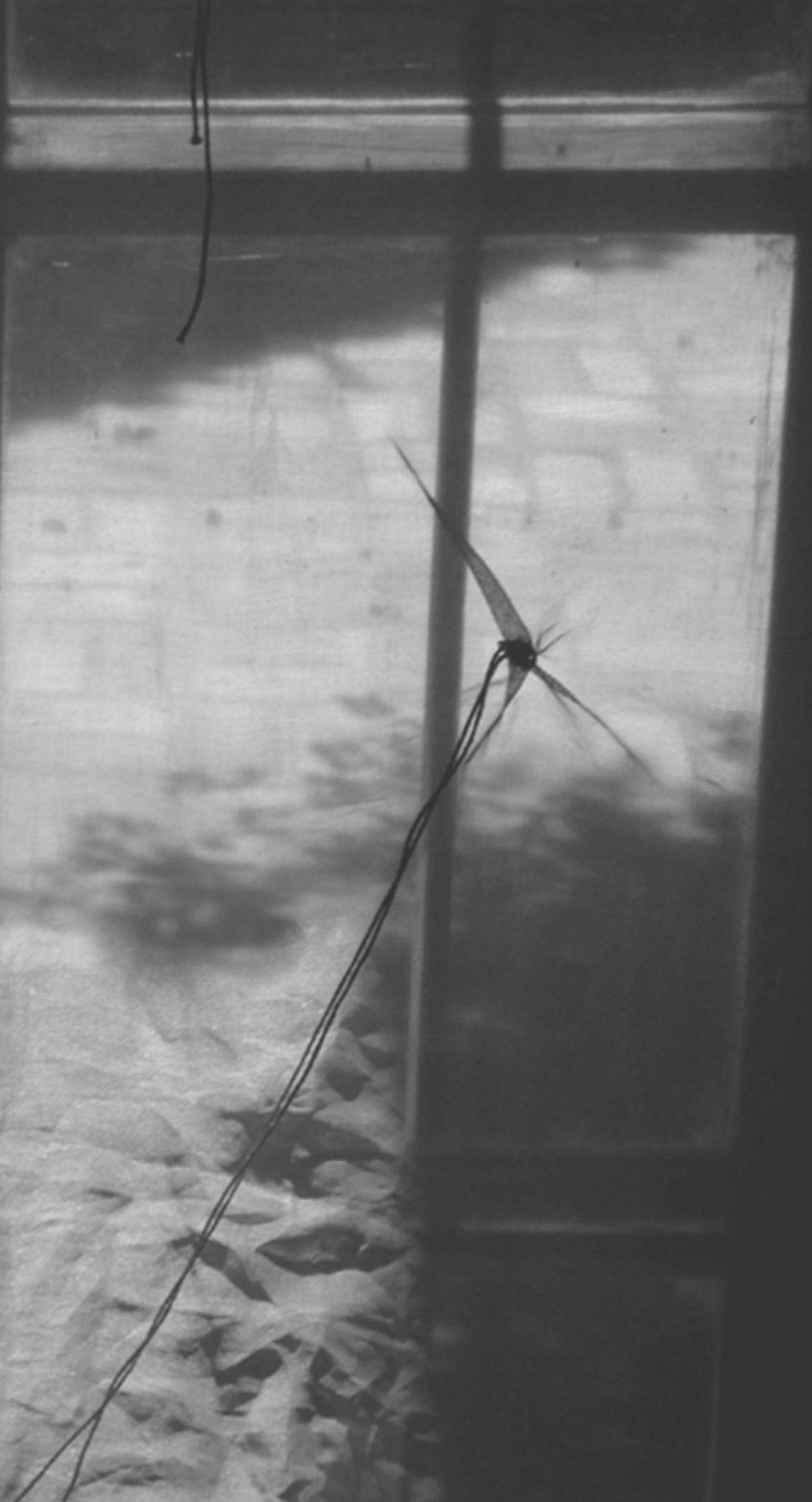

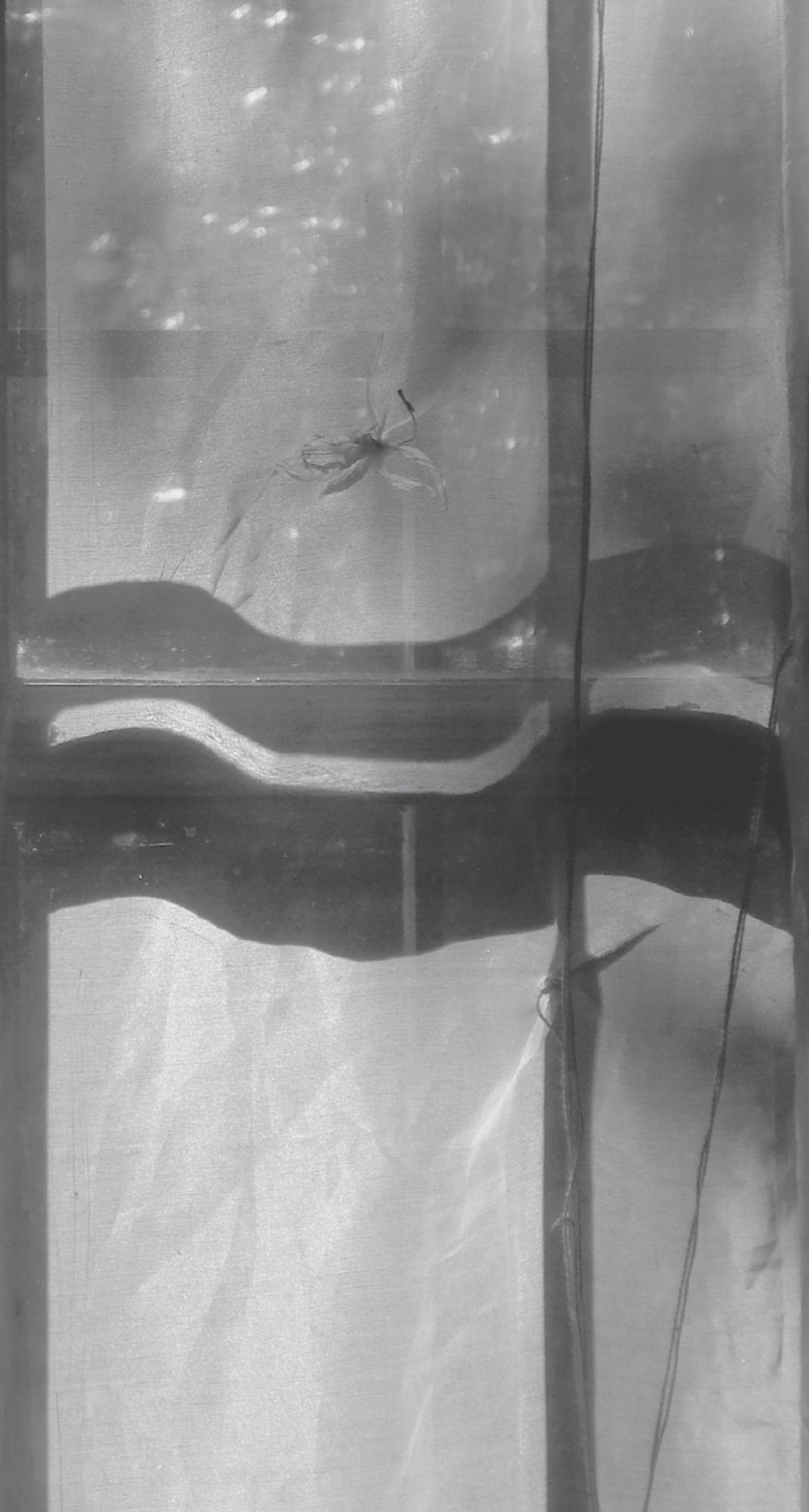

6 


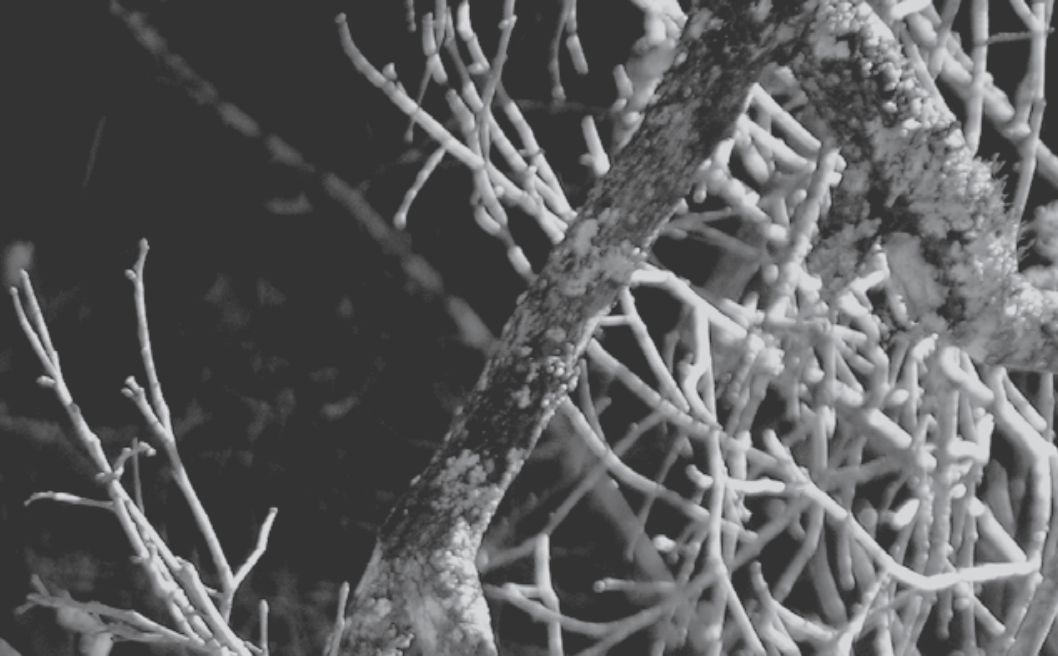
and 21

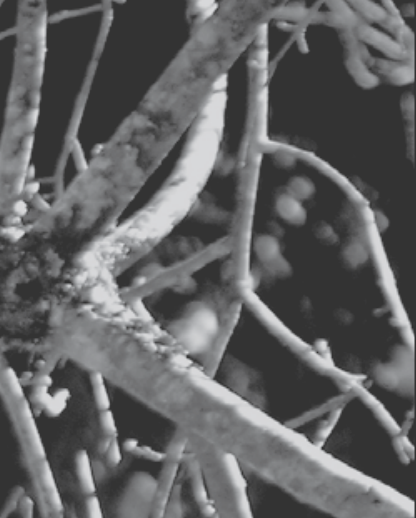

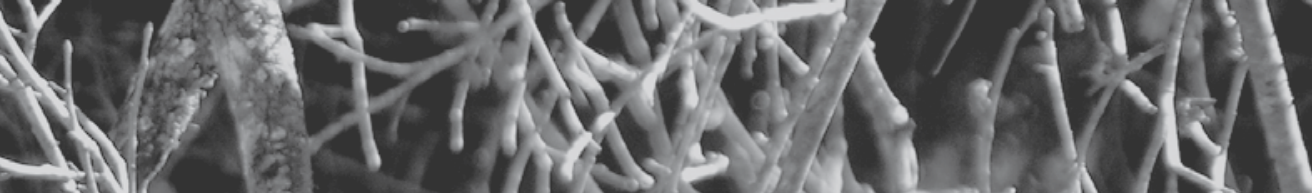

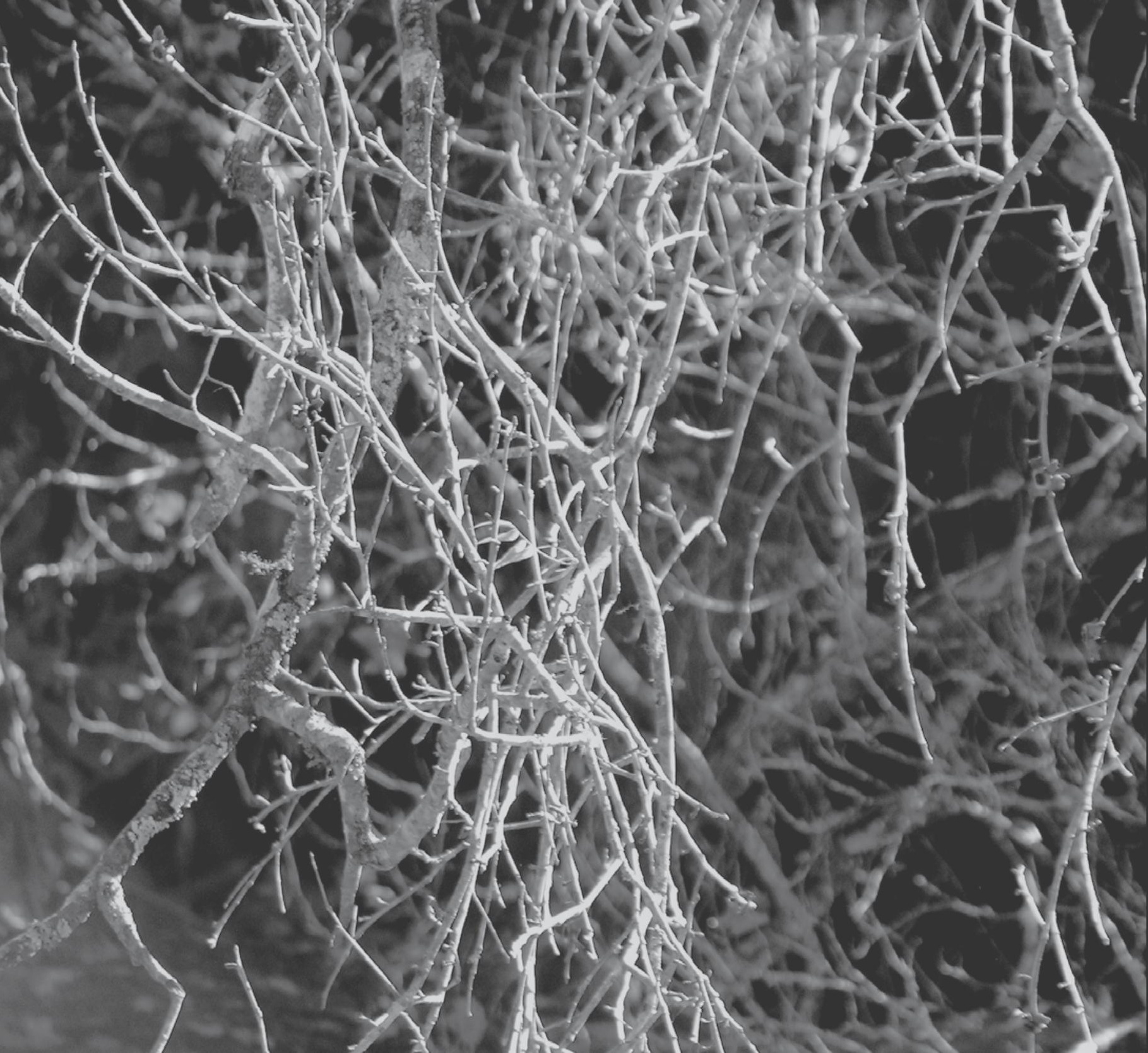




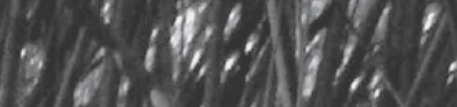

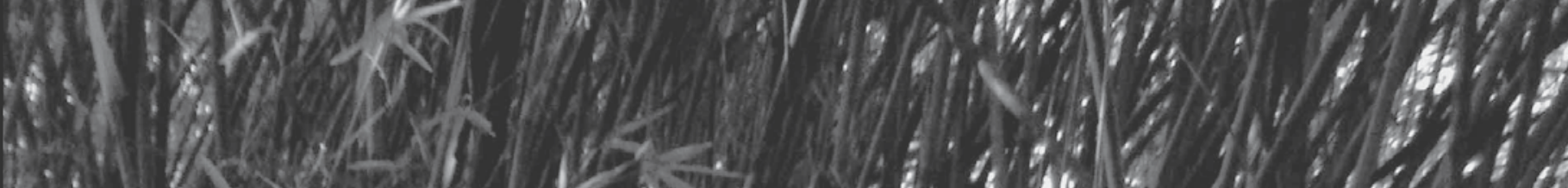

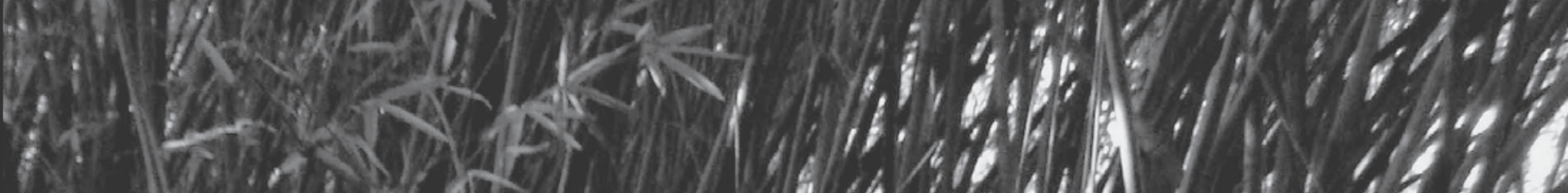

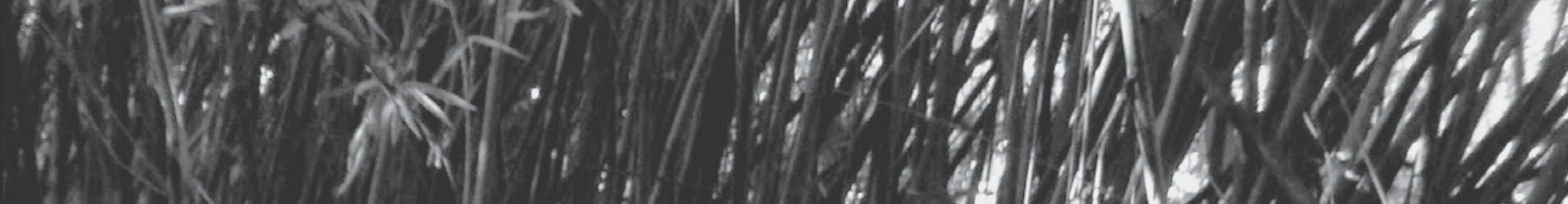
(1) 3.

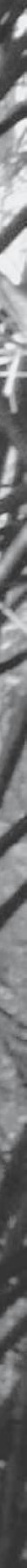
119211 
ensaio fotográfico, 2010 